\title{
Standardized Procedure of Transperineal Minimally Invasive Abdominoperineal Resection for Low Rectal Cancer
}

\author{
Takeru Matsuda, MD, $\mathrm{PhD}^{1,2}$, Ryuichiro Sawada, MD, $\mathrm{PhD}^{1}$, Hiroshi Hasegawa, MD, $\mathrm{PhD}^{1}$, \\ Kimihiro Yamashita, MD, PhD ${ }^{1}$, Masako Utsumi, MD ${ }^{1}$, Hitoshi Harada, MD, PhD ${ }^{1}$, Naoki Urakawa, MD, PhD $^{1}$, \\ Hironobu Goto, MD, $\mathrm{PhD}^{1}$, Shingo Kanaji, MD, $\mathrm{PhD}^{1}$, Taro Oshikiri, $\mathrm{MD}$, $\mathrm{PhD}^{1}$, and Yoshihiro Kakeji, $\mathrm{MD} \mathrm{PhD}^{1}$ \\ ${ }^{1}$ Division of Gastrointestinal Surgery, Department of Surgery, Kobe University Graduate School of Medicine, Kobe, Japan; \\ ${ }^{2}$ Division of Minimally Invasive Surgery, Department of Surgery, Kobe University Graduate School of Medicine, Kobe, \\ Japan
}

\begin{abstract}
Although transperineal minimally invasive abdominoperineal resection (tp-APR) based on the concept of transanal total mesorectal excision has recently been used for rectal cancer, the operative procedure has not been standardized to date due to its technical difficulty. The tp-APR procedure used by the authors for a male patient with low rectal cancer is presented in this video.

After the anus was tightly closed by double suturing, a circumferential skin incision around the anus was made. Then a single-port device was placed, and the perineal subcutaneous cavity was insufflated by carbon dioxide $\left(\mathrm{CO}_{2}\right)$ at $15 \mathrm{mmHg}$. The fat tissue of the ischioanal fossa was dissected, and the levator ani muscle at both sides was exposed.

Once the mesorectal plane was reached by dissection of the levator ani muscle at 6 o'clock, dissection of the levator muscle was extended bilaterally. Then the puborectalis sling was divided at 2 and 10 o'clock to expose the mesorectum completely. The dorsal surface of the prostate was identified by dissecting between the neurovascular
\end{abstract}

bundle and the mesorectum. Once the dorsal surface of the prostate was identified, the rectourethral muscle was divided by using it as a landmark. After dissection of the rectourethral muscle, total mesorectal excision was performed in a down-to-up manner until rendezvous was achieved. In this case, the rendezvous point was above the S3 pelvic splanchnic nerve.

This approach offers several advantages including shorter operative time, smaller perineal incision, and better visualization of the deep pelvis. This standardized procedure is reliable for safe performance of tp-APR.

Supplementary Information The online version contains supplementary material available at https://doi.org/10.1245/s10434021-11214-4.

DISCLOSURE There are no conflict of interest.

Publisher's Note Springer Nature remains neutral with regard to jurisdictional claims in published maps and institutional affiliations.

(C) Society of Surgical Oncology 2021

First Received: 27 September 2021

Accepted: 5 December 2021;

Published Online: 21 January 2022

T. Matsuda, $\mathrm{MD}, \mathrm{PhD}$

e-mail: takerumatsuda@nifty.com 